\title{
УСЛОВИЯ ОСЕННЕЙ ВЕГЕТАЦИИ И ПЕРЕЗИМОВКИ ОЗИМЫХ КУЛЬТУР В САРАТОВСКОЙ ОБЛАСТИ
}

\author{
Саратовский государственный университет, \\ кафедра метеорологии и климатологии \\ E-mail: kafmeteo@sgu.ru \\ ${ }^{1}$ кафедра геоморфологии и геоэкологии \\ E-mail: geogr@sgu.ru
}

С.И. Пряхина, Ю.А. Скляров, М.Ю. Васильева' ${ }^{1}$ Ю.Н. Фридман

Анализ ежедневного метеорологического материала за 67-летний период позволил подобрать критерии оценки закаливания и перезимовки озимых культур в осенне-зимний период. Самая большая повторяемость неблагоприятных зим наблюдалась в 60-е годы. В последние три десятилетия повышение температуры и увеличение осадков в зимний период создают благоприятные условия для возделывания озимых культур в Саратовской области.

Ключевые слова: озимые, фаза закаливания, перезимовка, вегетация, осадки, цикл развития, урожайность, сумма температур, узел кущения, гибель посевов, морозостойкость, потепление климата.

\section{Conditions of autumn Vegetation and Wintering of Winter Crops in Saratov Region}

\section{S.I. Pryakhina, Yu.A. Sklyarov, M.Yu. Vasilieva, Yu.N. Fridman}

The analysis of meteorological data obtained daily for 67 years was made to select the criteria for evaluation of hardiness and wintering of winter crops. The highest repetition frequency of disadvantageous winters was observed in 1960-s. The increase of temperature and precipitation during the winter in the past thirty years has created advantageous conditions for cultivation of winter crops in Saratov Region.

Key words: winter crops, hardening phase, hibernation, precipitations, development cicle, productivity, temperatures sum, bushing out centre, loss of sowing, frost-resistence, elimate warming.

Во многих районах нашей страны озимая рожь и пшеница являются основными зерновыми культурами. Пшеница в силу своих высоких питательных и вкусовых качеств является одним из главнейших злаков мира и играет во многих государствах ведущую роль в питании населения.

Используя осенне-зимние запасы почвенной влаги, корневая система озимых культур глубоко проникает в почву, благодаря чему они мало страдают от недостатка влаги в верхнем слое почвы. Относительно раннее созревание приводит к сравнительно меньшему, чем у яровых культур, повреждению озимых засухами и суховеями. Урожайность озимых существенно выше многих яровых зерновых культур.

Хорошие климатические условия для возделывания озимых зерновых культур складываются на европейской части страны, где в настоящее время размещается более $80 \%$ их посевных площадей.

В Саратовской области зерновые культуры занимают более 55\% пашни, или 69\% всех посевных площадей [1].

Условия формирования и пути повышения урожайности озимых зерновых культур нельзя рассматривать в отрыве от природноклиматических особенностей региона и погодных условий конкретного года.

В данной статье рассмотрены условия осенней вегетации и перезимовки озимых культур в Саратовской области.

Весь период роста и развития озимых зерновых культур делится на три цикла. Первый цикл проходит от посева до осеннего глубокого похолодания. За время этого цикла стебли и репродуктивные органы остаются в зачаточном состоянии, но идет усиленный рост листьев, боковых побегов и корневой системы.

За второй цикл развития растений происходит приостановка роста и наступает период естественного, а затем вынужденного покоя. И наконец, третий цикл - это период интенсивного роста, он начинается с возобновления вегетации и заканчивается формированием урожая и отмиранием растений. Первый и второй циклы связаны с подготовкой растения к перезимовке и с его перезимовкой, а от условий зимовки зависит жизнь всего растения и его продуктивность.

В осенний период происходит закаливание растений, которое проходит в две фазы. Первая фаза закаливания происходит при дневной температуре $6-10^{\circ} \mathrm{C}$ и при ночной - около $0^{\circ} \mathrm{C}$. При таких условиях накопление углеводов в растениях за счет фотосинтеза днем превышает их расход на рост и дыхание. Накапливающиеся углеводы являются защитным материалом против низких температур. Морозостойкость растений сильно зависит от стадии развития растений перед началом их вступления в зиму. Именно здесь сроки сева озимой пшеницы приобретают первостепенное значение, т.е. лучше закаляются растения оптимальных сроков и хуже - поздних и ранних.

Вторая фаза закаливания проходит при небольших морозах, в начале периода покоя. 
Растения хорошо проходят первую фазу закаливания, если осенью наблюдалось более 40 дней со средней суточной температурой от 10 до $0^{\circ} \mathrm{C}$ и в августе и сентябре выпало более $80 \mathrm{Mм}$ осадков [2].

С удовлетворительной осенней закалкой отмечены осенние периоды, когда наблюдалось 30-40 дней со средней суточной температурой от 10 до $0^{\circ} \mathrm{C}$ и выпало осадков за август, сентябрь от 80 до 50 мм.

Осень считается плохой, если во время посева озимых стоит сухая погода и сумма осадков за август и сентябрь не превышает 50 мм, число дней с температурой от 10 до $0^{\circ} \mathrm{C}$-менее 30 дней.

Вышеуказанные критерии и были положены в основу оценки состояния озимой пшеницы в осенний период. Было выделено три комплекса благоприятности: неблагоприятный с оценкой в 1 балл, удовлетворительный - в 2 балла и благоприятный -3 балла.

Оценка исходного материала показала, что самые благоприятные условия осенней вегетации отмечались в 80 и 90-е гг. XX столетия, когда повторяемость неблагоприятных условий вегетации составляла 2 и 1 случай за десятилетие, а средний балл оценки осенней вегетации составил 2,2 и 2,3. В первом десятилетии XXI столетия 2005 год отмечен как неблагоприятный из-за недостатка осадков и большой гибели посевов (табл.1).

Таблица 1

Повторяемость типов погодных условий по степени благоприятности в осенний период по десятилетиям по ст. Саратов

\begin{tabular}{|c|c|c|c|c|c|}
\hline \multirow{2}{*}{ Годы } & \multicolumn{3}{|c|}{ Типы погодных условий } & \multirow{2}{*}{ Сумма баллов } & \multirow{2}{*}{ Средний балл } \\
\cline { 2 - 4 } & III & II & I & 18 & 2,0 \\
\hline $1962-1970$ & 3 & 3 & 3 & 21 & 2,1 \\
\hline $1971-1980$ & 4 & 3 & 2 & 22 & 2,2 \\
\hline $1981-1990$ & 4 & 4 & 1 & 23 & 2,3 \\
\hline $1991-2000$ & 4 & 5 & 1 & 13 & 2,1 \\
\hline $2001-2006$ & 2 & 3 & & & \\
\hline
\end{tabular}

Ниже приводятся результаты анализа ежедневного метеорологического материала за 67-летний период по условиям перезимовки озимых культур.

Перезимовка сельскохозяйственных культур определяется биологическими особенностями растений, их состоянием в период прекращения осенней вегетации, степенью закалки и агрометеорологическими условиями холодного периода.

Решающим фактором перезимовки озимых культур является температура почвы на глубине узла кущения (3 см), которая определяется главным образом температурой воздуха, высотой снежного покрова и глубиной промерзания почвы.

Критическая температура вымерзания слаборазвитой озимой пшеницы при плохих условиях осенней закалки составляет $-15^{\circ}-\left(-17^{\circ}\right)$, для хорошо развитой $-\left(-18^{\circ}\right)-\left(-20^{\circ}\right)$, а для озимой ржи $-\left(-18^{\circ}\right)-\left(-20^{\circ}\right)$ и $21^{\circ}-\left(-23^{\circ}\right)$ соответственно.

Температура воздуха определяет не только условия, но и продолжительность периода зимовки растений, который начинается с устойчивого перехода средней суточной температуры воздуха через $0^{\circ} \mathrm{C}$ осенью и заканчивается при переходе ее к положительным значениям весной. В зависимости от сроков перехода температуры воздуха через $0^{\circ} \mathrm{C}$ осенью и весной продолжительность периода зимовки год от года значительно меняется. В течение зимнего периода растения подвергаются влиянию ряда неблагоприятных факторов. Поэтому чем длиннее период зимовки, тем больше вероятность повреждения и гибели растений. Холодный период года является периодом покоя для зимующих культур. Он разделяет между собой два цикла развития озимых культур - осенний и весенне-летний. Урожай озимых культур зависит от агрометеорологических условий не только теплого, но и холодного времени года. Во многих случаях именно условия перезимовки определяют урожай озимых культур.

Оценка условий перезимовки была проведена на ежедневном метеорологическом материале за 67-летний период (1941-2007 гг.) по станции Саратов.

Средняя продолжительность зимнего периода за 67 лет составила 137 дней. За это время она изменялась от 92 дней в 1990 г. до 171 дня в 1976 году. С 1951 по 1960 г. средняя продолжительность зим составляла 150 дней. В последующие десятилетия продолжительность зим уменьшается и не превышает в среднем 137 дней. Самые непродолжительные зимы (130 дней) отмечаются в последнее десятилетие (2001-2007 гг.) (рис. 1).

В последние три десятилетия переход температуры через $0{ }^{\circ} \mathrm{C}$ в осеннее время сместился на более поздние, а в весеннее на более ранние сроки (на 7-8 дней).

Температура воздуха в период зимовки имеет хорошо выраженный суточный ход. Самым холодным периодом являются январь и первая половина февраля. Особенно сильно влияет температура воздуха на перезимовку озимых культур при отсутствии снежного покрова или малой его высоте.

Были подсчитаны средние суточные температуры воздуха с ноября по март за каждый зимний сезон. Средняя многолетняя сумма от- 


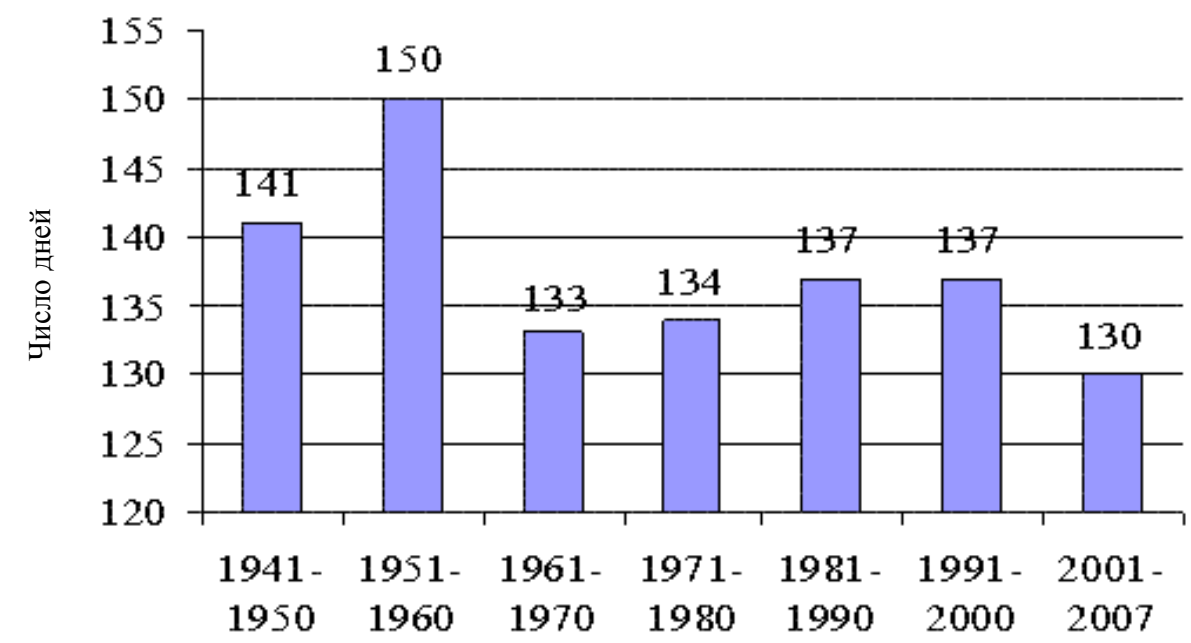

Рис. 1. Средняя продолжительность зимнего периода по десятилетиям

рицательных температур за 67-летний период составила $-1041^{\circ} \mathrm{C}$. Все зимы, набравшие суммы отрицательных температур более $120 \%$ от средней многолетней, были отнесены к холодным зимам, а менее $80 \%$ от средней многолетней - к теплым. Таким образом, зима считалась теплой, если сумма отрицательных температур за ноябрь-март составляла $800^{\circ} \mathrm{C}$ и менее, нормальной $-800-1200^{\circ} \mathrm{C}$ и холодной - более $1200^{\circ} \mathrm{C}$. Самый холодный зимний период наблюдался в 1941/42 гг., когда сумма отрицательных температур составила $-1651,2^{\circ} \mathrm{C}$, самый теплый - 1989/90 гг. В этот зимний сезон сумма отрицательных температур составила всего $-362,4^{\circ} \mathrm{C}$.

Средняя сумма температур за зимний период по десятилетиям: 1941-1950, 1951-1960, 1961-1970, 1971-1980, 1981-1990, 1991-2000, 2001-2007 гг. составила соответственно -1174, $-1214,-1040,-932,-875,-864,-668^{\circ} \mathrm{C}$ (рис. 2).

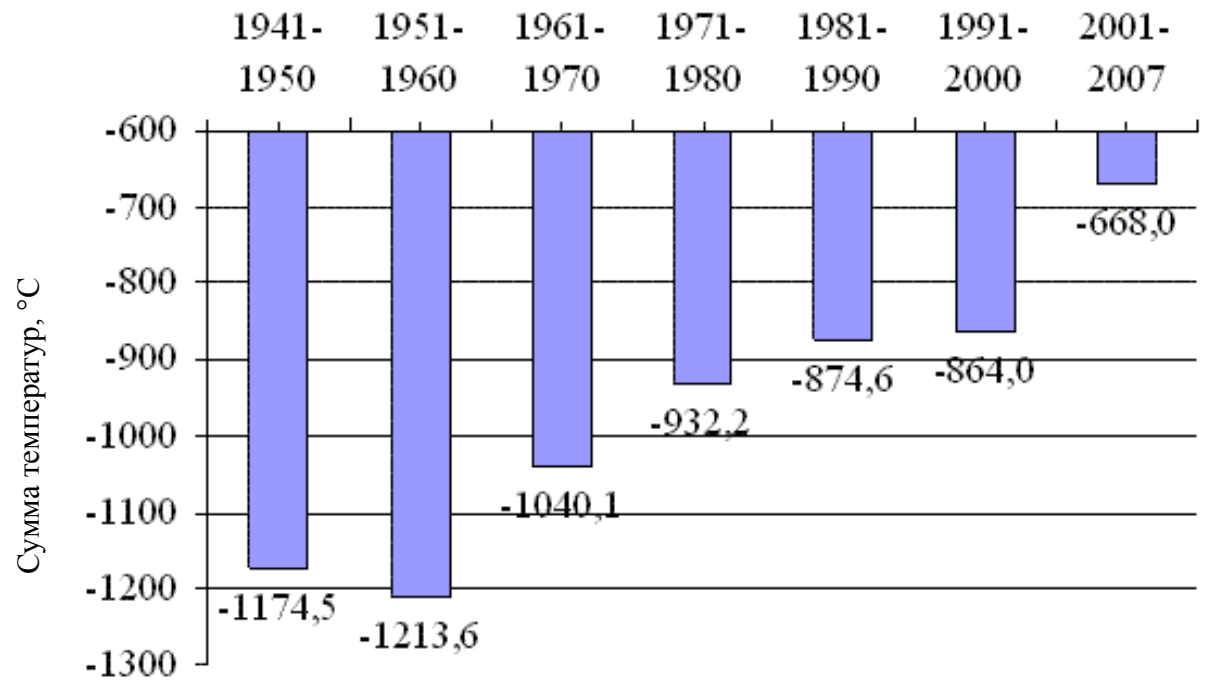

Рис. 2. Средняя сумма температур за зимний период по десятилетиям

На основе фактических данных были выделены холодные, нормальные и теплые зимы. За 67-летний период отмечалось холодных зим 17, нормальных 30 и теплых 20. Если проанализировать зимы по десятилетиям, то видно, что с 1941 по 1950 г. на 4 холодные зимы с суммами температур $-1401,9^{\circ} \mathrm{C}$, $-1651,2^{\circ} \mathrm{C},-1558,6^{\circ} \mathrm{C},-1212,6^{\circ} \mathrm{C}$ приходилось 6 нормальных зим и ни одной теплой. В следующем десятилетии на 6 холодных зим приходилось
4 нормальные и ни одной теплой. С 60-х гг., или с третьего десятилетия (1961-1979 гг.), появляются 2 теплые зимы. В последующие десятилетия видно, что теплые зимы являются преобладающими, а в последнее десятилетие (2001-2007 гг.) на 5 теплых зим приходилось 2 нормальные зимы с суммами температур менее $-1000^{\circ} \mathrm{C}$ (табл.2).

Тенденцию потепления зимнего сезона демонстрируют рис. 2 и табл. 2. 
Повторяемость холодных, теплых и нормальных зим по ст.Саратов за 1941-2007 гг.

\begin{tabular}{|c|c|c|c|}
\hline Годы & Холодные & Нормальные & Теплые \\
\hline $1941-1950$ & 4 & 6 & - \\
\hline $1951-1960$ & 6 & 4 & 2 \\
\hline $1961-1970$ & 2 & 6 & 2 \\
\hline $1971-1980$ & 1 & 7 & 5 \\
\hline $1981-1990$ & 2 & 2 & 5 \\
\hline $1991-2000$ & 2 & 2 & \\
\hline $2001-2007$ & 0 & & \\
\hline
\end{tabular}

Понижение температуры почвы на глубине узла кущения до критических значений наблюдается в период сильных морозов при отсутствии снежного покрова. Для благоприятной перезимовки растений необходимо определенное соотношение температуры воздуха и высоты снежного покрова.

В основу оценки зим по характеру их снежности был положен критерий, разработанный П.Г. Кабановым [3], согласно которому зима считалась бесснежной, если высота снежного покрова не превышала 16 см, малоснежной - 16-25 см и снежной - более 25 см. За критерий благоприятности сложившихся агрометеорологических условий в период перезимовки озимых взят процент гибели растений на дату весеннего обследования посевов после возобновления их вегетации.

В годы, когда гибель посевов превышала $25 \%$, условия зимовки оценивались как неблагоприятные [4,5].

Если поврежденных посевов было от 11 до $24 \%$, то условия зимовки оценивались как удовлетворительные, когда поврежденных посевов было менее $10 \%$, зимовка считалась хорошей.

Оценка отдельных типов погодных условий, приводящих к тому или иному проценту гибели растений к весне, позволила выделить следующие комплексы агрометеорологических условий перезимовки и оценить их по трехбалльной шкале.

К неблагоприятному типу с оценкой в 1 балл отнесены холодные малоснежные и бесснежные зимы, а также теплые бесснежные зимы с наличием притертых ледяных корок и вымерзанием посевов более $25 \%$. Удовлетворительной, с оценкой 2 балла, считалась зимовка при теплых и нормальных малоснежных и бесснежных зимах, когда гибель от притертых ледяных корок и вымерзания составляла от 11 до $24 \%$.

Благоприятная зимовка с оценкой в 3 балла и гибелью посевов менее $10 \%$ приходилась в основном на теплые и нормальные малоснежные и бесснежные зимы.

Оценка фактического материала за каждый зимний период и по десятилетиям показала, что самая большая повторяемость неблагоприятных зим с оценкой в 1 балл наблюдалась в 60-е годы. С потеплением климата и увеличением теплых зим сокращается повторяемость зим с оценкой в 1 балл и увеличивается повторяемость зим с оценкой 2 и 3 балла. В 90-е годы неблагоприятных зим не наблюдалось (табл. 3).

Таблииа 3

Повторяемость типов погодных условий по степени благоприятности для перезимовки озимых культур

\begin{tabular}{|c|c|c|c|c|c|}
\hline \multirow{2}{*}{ Годы } & \multicolumn{3}{|c|}{ Типы погодных условий } & \multirow{2}{*}{ Сумма баллов } & \multirow{2}{*}{ Средний балл } \\
\cline { 2 - 4 } & III & II & I & 12 & 1,5 \\
\hline $1963-1970$ & 1 & 3 & 3 & 25 & 2,5 \\
\hline $1971-1980$ & 6 & 3 & 2 & 21 & 2,1 \\
\hline $1981-1990$ & 3 & 5 & & 24 & 2,4 \\
\hline $1991-2000$ & 4 & 6 & & & \\
\hline
\end{tabular}

Исследованиями установлено, что региональное проявление глобального потепления климата выражается в увеличении среднегодовой температуры воздуха на $1,1^{\circ} \mathrm{C}$, а зимнего сезона - на $2,1^{\circ} \mathrm{C}$, теплообеспеченность вегетационного периода увеличилась на $140-150^{\circ}$, а его продолжительность - на 8-10 дней. Годовая сумма осадков увеличилась на 24 мм, а количество осадков маяавгуста уменьшилось на 13 мм.
Повторяемость устойчивых засух сильной интенсивности с гидротермическим коэффициентом менее 0,5 увеличилось с 12 до $27 \%$.

Выявленные тенденции в изменении основных агрометеорологических характеристик демонстрируют, что наблюдающиеся в последние три десятилетия повышение температуры и увеличение осадков в зимний период создают благоприятные условия для возделывания озимых культур. 


\section{Библиографический список}

1. Агроклиматические ресурсы Саратовской области. Л., 1970. 123c.

2. Пряхина С.И., Скляров Ю.А., Левицкая Н.Г. Агрометеорологические прогнозы: Учеб.-метод. пособие. 2-е изд., доп. Саратов, 2006. 72 с.
3. Кабанов П.Г. Погода и поле. Саратов, 1975. 235 с.

4. Пряхина С.И. Структура и продолжительность климатических сезонов г. Саратова. М., 1966. 10 с. Деп. в ВИНИТИ. №1524-В96.

5. Левицкая Н.Г. Повышение эффективности использования биоклиматического потенциала агроландшафтов Саратовского Правобережья: Автореф. дис. ... канд. с.-х. наук. Саратов, 2003. 19 с.

УДК 528 (470.44)

\section{КАРТОГРАФИЧЕСКАЯ МОДЕЛЬ ГЕОЭКОЛОГИЧЕСКОЙ ОЦЕНКИ ТЕРРИТОРИИ}

\section{В.К. Штырова, О.Е. Нестерова \\ Саратовский государственный университет, кафедра геоморфологии и геоэкологии E-mail: Nesterova@sgu.ru}

В статье рассматривается методика создания картографической модели геоэкологического состояния территории. Приводится поэтапное описание процесса создания карт и их назначение. Обосновывается важность использования рельефа в качестве объекта картографирования при создании геоэкологической карты.

Ключевые слова: картографическая модель, геоэкология, рельеф, природно-техногенные процессы, природопользование, легенда, способы изображения.

\section{Model of the Geoecological Assessment of a Territory}

\section{V.K. Shtyrova, O.E. Nesterova}

In this article the method of creation a cartographic model of the geoecological situation of a territory is considered. The description of maps creation and their purpose is given. The necessity of relief using as the object of mapping in the creating a geoecological map is justified.

Key words: cartographic model, geoecology, relief, natural-technogenic processes, wildlife management, legend, ways of the image.

Комплексное картографирование определяется К.А. Салищевым как метод многостороннего и целостного показа действительности картографическими средствами.

Комплексное системное картографирование может являться в этой связи основой комплексной геоэкологической оценки территории.

Сущность геоэкологического картографирования заключается в системном отображении, во-первых, комплекса природных и техногенных факторов в их взаимосвязи, динамики и, вовторых, в организации самого картографирования.

Особенности этого вида картографирования сводятся к следующим принципам:

1) основой геосистемного исследования служит картографическая модель геосистемы, соответствующая задачам, тематике, уровню генерализации, масштабу исследования;

2) основное внимание сосредотачивается на

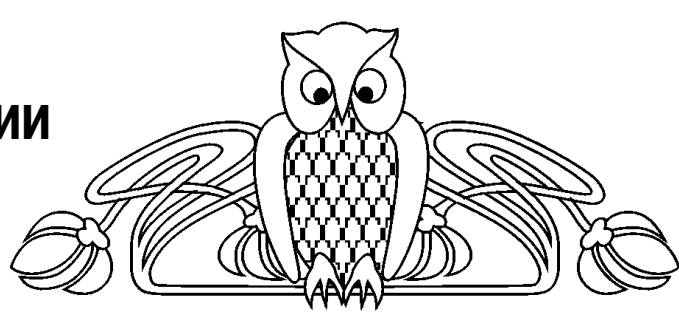

выявлении и картографировании системообразующих связей;

3) вслед за этим выясняется пространственная структура геосистемы, ее организация, динамика, функционирование, изучаются процессы обмена веществом и энергией, анализируются возможности управления геосистемой.

С помощью картографических моделей, по мнению А.М. Берлянта, осуществляются упорядоченный сбор и обработка информации, ведение дистанционных наблюдений, регистрация состояния, динамики и функционирования геосистем. Основными документами для исследований служат системы карт. В соответствии с поставленной целью составляют карты различной тематики, разновременные, разного масштаба и степени синтеза. При этом речь идет не просто об использовании больших и разнообразных комплектов тематических карт, а об оптимальном наборе для каждого конкретного случая [1].

Единой научно-обоснованной методики подобного картографирования пока не разработано, но существует достаточно много региональных схем.

Предложенная нами методика геоэкологической оценки территории построена на наличии большого фактического материала, выводит на составление картографической модели геоэкологической обстановки и апробирована на территориях Новоузенского, Саратовского, Советского и других районов Саратовской области, нефтегазоносных месторождениях Крайнего Севера.

Основой картографического решения поставленной задачи являлись топографические и тематические карты масштабов 1:100 000, 1:200 000, 1:500 000.

Создание картографической модели осуществлялось поэтапно следующим образом.

Первый этап включает в себя сбор и обработку информации, характеризующей совре- 